\title{
Logística Reversa dos Pneus Usados no Brasil
}

\author{
Carlos A. F. Lagarinhos, Jorge A. S. Tenório \\ Departamento de Engenharia Metalúrgica e de Materiais, EPUSP
}

\begin{abstract}
Resumo: Após a aprovação da Resolução CONAMA (Conselho Nacional do Meio Ambiente) nº 258/99, ocorreu um avanço significativo na reciclagem de pneus no Brasil, com o desenvolvimento de tecnologias para reutilização, reciclagem e valorização energética. Em 2009, foi aprovada a Resolução CONAMA nº 416/09 que muda a forma de cálculo para a reciclagem, de pneus produzidos para venda no mercado de reposição. O objetivo principal deste trabalho é apresentar a logística reversa dos pneus usados no Brasil e comparar com os sistemas implementados no Japão, Estados Unidos e Comunidade Européia. No período de 1999 até 2010, foram destinados 2,44 milhões de toneladas, o equivalente a 487,6 milhões de pneus inservíveis de automóveis.
\end{abstract}

Palavras-chave: Logística-reversa, legislação, reciclagem.

\section{Reverse Logistics for Post-Consumer Tires in Brazil}

Abstract: After the CONAMA (National Council for Environment) resolution 258/99, significant improvement occurred in the recycling of tires in Brazil, with technologies being developed for reusing, recycling and energy recovery. In 2009, the CONAMA 416/09 resolution changed the formula for calculating the recycling of tires, to be sold in the replacement market. The main objective in this work is to present the reverse logistics of used tires in Brazil and compare it with the systems already implemented in Japan, Europe and USA. From 1999 to 2010, were recycled 2.44 million tons, corresponding to 487.6 million automotive tires.

Keywords: Reverse Logistics, legislation, recycle.

\section{Introdução}

O rápido desenvolvimento tecnológico, aumento da população e demanda por novas tecnologias com redução do ciclo de vida dos produtos tem contribuído para o aumento do descarte, como consequência ocorre o aumento do volume destinado para aterros, consumo de recursos naturais, energia, poluição do ar, das águas superficiais e subterrâneas, aumento dos custos envolvidos no processo de coleta e destinação dos resíduos e esgotamento dos aterros próximo dos pontos de geração de resíduos.

Com o aumento da conscientização da população, pela preservação do meio ambiente e saúde pública, tem se definido políticas federais, estaduais e municipais. Além disso, mudança na postura das empresas com relação ao projeto de produtos e a preocupação com relação a sua disposição final.

Uma proposta iniciada em 1999, para a regulamentação dos resíduos sólidos no Brasil, foi a Política Nacional de Resíduos Sólidos (PNRS), que provocou uma mudança na postura do CONAMA em relação à normatização da área de resíduos. A partir de 1998, o CONAMA iniciou um trabalho de regulamentação sobre os seguintes resíduos: pneus, pilhas e baterias, serviços de saúde, construção civil, importação e exportação, lâmpadas fluorescentes, aterros sanitários, entre outros.

Com a aprovação da PNRS ${ }^{[1]}$, em 2 de agosto de 2010, os fabricantes, distribuidores, importadores e comerciantes de agrotóxicos, pilhas e baterias, pneus, óleos lubrificantes, lâmpadas fluorescentes, de vapor de sódio e mercúrio e de luz mista, produtos eletrônicos e seus componentes, estão obrigados a desenvolverem um sistema de logística reversa para o retorno de produtos e embalagens no final da vida útil, que independe do serviço público de limpeza urbana. Além disso, determina que a gestão dos resíduos seja de responsabilidade de todos: governo federal, estados, municípios, empresas e sociedade.

Em 23 de dezembro de 2010, foi regulamentada a Lei $\mathrm{n}^{\mathrm{o}} 12.305$, de 2 de agosto de $2010^{[2]}$, que institui a PNRS, cria o Comitê Interministerial da Política Nacional de Resíduos Sólidos e o Comitê Orientador para a implantação dos Sistemas de Logística Reversa, entre outras.

\section{Metodologia}

Foi realizada uma pesquisa junto as associações dos fabricantes, reformadores de pneus, recicladores; secretária de comércio exterior, órgãos ambientais, pontos de coleta, para o desenvolvimento de um modelo de logística reversa para os pneus usados no Brasil. Além disso, foi feito um levantamento das associações que representam os fabricantes nos Estados Unidos, Japão e Comunidade Européia, para fazer um comparativo do modelo utilizado no Brasil, em termos de legislação, custos, sistemas utilizados e suas respectivas tecnologias para a reutilização, reciclagem e a valorização energética.

\section{Produção de Pneus no Brasil}

Em 2010, foram fabricados 67,3 milhões de pneus, exportados 18,1 milhões e importados 23,9 milhões. Os principais canais de distribuição foram: $45 \%$ para o mercado de reposição e revenda; $30 \%$ para as indústrias automobilísticas e montadoras; e 25\% para a exportação ${ }^{[3]}$. A evolução da produção, vendas, importação e exportação de pneus novos no período de 2002 a 2010 são apresentadas na Figura 1. No período de 2002 a 2010 foram produzidos no Brasil 493,7 milhões de pneus.

\section{Legislação no Brasil}

Em 26 de agosto de 1999, foi aprovada a Resolução CONAMA $\mathrm{n}^{\mathrm{o}} 258 / 99^{[4]}$, que fixava as metas e obrigava os fabricantes e importadores a darem destinação final aos pneus inservíveis. Desde 2002, os fabricantes e importadores de pneus devem coletar e dar destinação final aos pneus inservíveis. Além disso, os distribuidores, revendedores, reformadores e consumidores finais são co-responsáveis pela coleta dos pneus usados. 


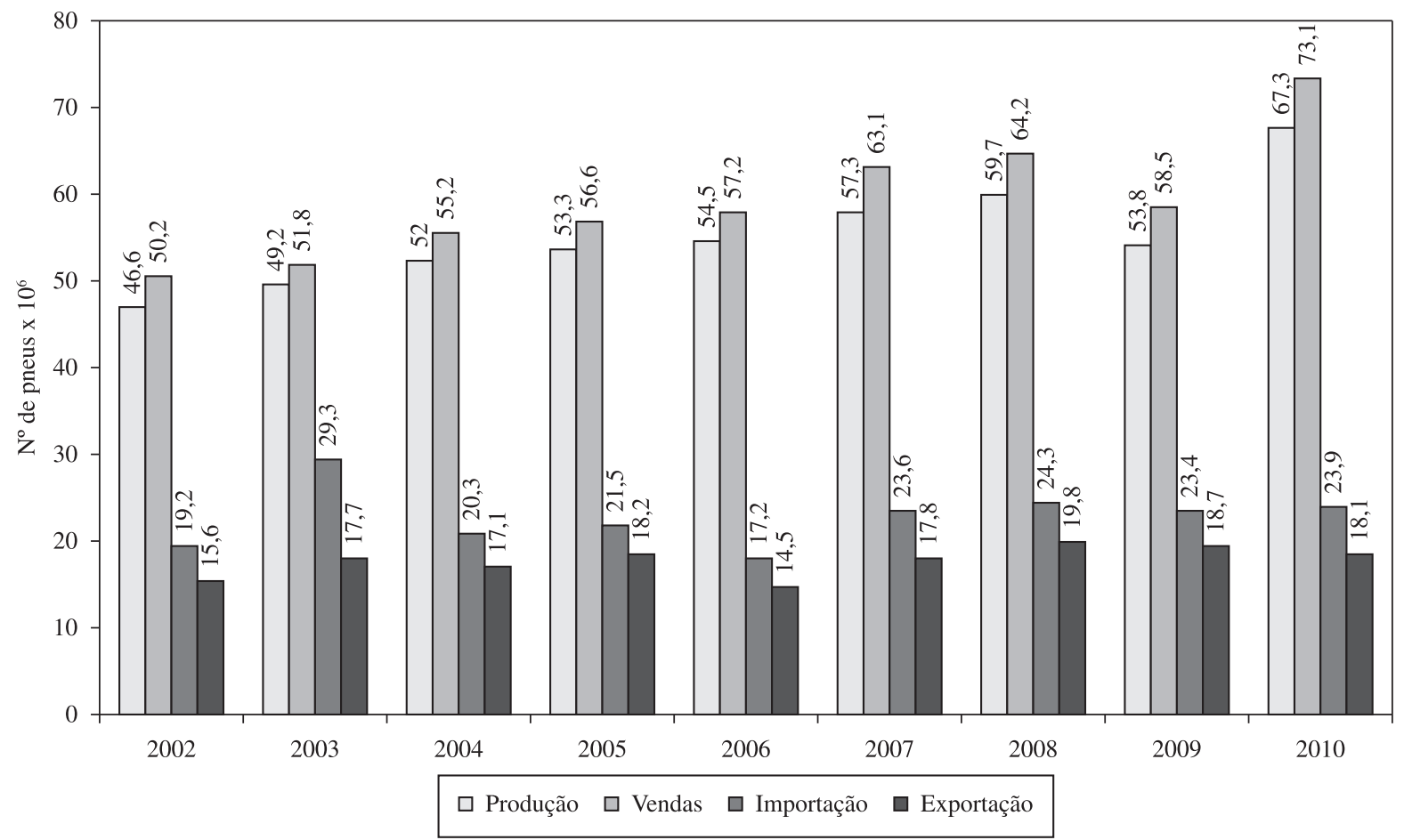

Figura 1. Mercado para os pneus novos, no período de 2002 a $2010^{[3]}$.

Antes da aprovação da legislação brasileira, somente $10 \%$ dos pneus eram reciclados. Após a aprovação da legislação, o número de empresas cadastradas para recolher e destruir os pneus inservíveis, que estão de acordo com a Instrução Normativa $\mathrm{n}^{\mathrm{o}}$ 008/02 $2^{[5]}$ do Instituto Brasileiro do Meio Ambiente e dos Recursos Naturais Renováveis (IBAMA), passou de 4 para 65. Em 2010, são 124 empresas cadastradas no IBAMA para a reutilização, reciclagem e a valorização energética dos pneus.

Um número desconhecido de empresas atua no mercado informal. Além disso, os fabricantes e importadores montaram estruturas de coleta, pré-tratamento e destinação final dos pneus inservíveis.

A tendência é o aumento da quantidade de pneus inservíveis descartados nos próximos anos, devido o aumento da frota de veículos no país. No caso da cadeia de reciclagem de pneus houve o aumento do número de empresas cadastradas no IBAMA, com o desenvolvimento de novas tecnologias para a utilização dos materiais reciclados e a valorização energética. O Brasil já possui capacidade para a reciclagem e a valorização energética de todos os pneus inservíveis gerados no país anualmente.

A Resolução CONAMA no 258/99 entrou em revisão em 2006 pelo IBAMA e em setembro de 2009 foi aprovada a Resolução CONAMA $n^{\circ} 416 / 09^{[6]}$ que altera a forma de cálculo de produção para o mercado de reposição. A nova resolução coloca como desafio aos fabricantes e importadores a obrigação de dar destinação a $100 \%$ dos pneus que entram no mercado de reposição. A forma de cálculo para o mercado de reposição:

$\mathrm{MR}=[(\mathrm{P}+\mathrm{I})-(\mathrm{E}+\mathrm{EO})] \times 0,7$

MR = Mercado de reposição de pneus/meta de reciclagem;

$\mathrm{P}=$ total de pneus produzidos (em peso);

$\mathrm{I}=$ total de pneus importados (em peso);

$\mathrm{E}=$ total de pneus exportados (em peso); e

$\mathrm{EO}=$ total de pneus que equipam veículos novos (em peso).

De acordo com a lei, para cada pneu novo comercializado no mercado de reposição, os fabricantes e importadores devem dar uma destinação para um pneu inservível. A quantidade a ser reciclada deve ser convertida em peso, e deve ser aplicado um fator de desgaste de $30 \%$ sobre o peso do pneu novo produzido ou importado.

Os pneus inservíveis podem ser armazenados em lascas ou triturados em local adequado para armazenamento, desde que obedecidas às exigências para o licenciamento, pelo prazo de um ano, podem ser utilizados como comprovação junto ao IBAMA.

Os fabricantes e importadores de pneus novos devem elaborar um plano de gerenciamento de coleta, armazenamento e destinação final dos pneus inservíveis no prazo de seis meses após a publicação da Resolução $n^{\circ} 416 / 09$. Devem instalar nos municípios, com mais de 100.000 habitantes, pelo menos 1 ponto de coleta no prazo máximo de 1 ano após a publicação desta Resolução. A nova Resolução não considera a reforma de pneus como reciclagem e sim como uma atividade que prolonga a vida útil dos pneus.

A Instrução Normativa $n^{\text {o }} 001 / 2010^{[7]}$ do IBAMA regulamenta o procedimento que os fabricantes e importadores devem obedecer para o cadastro, cálculo das metas e comprovação da destinação. As Instruções Normativas no 008/2002, nº 018/2002 e n 021/2002 foram revogadas.

Segundo o deputado federal Arnaldo Jardim, coordenador do grupo de trabalho de resíduos sólidos da câmara, formado para avaliar a PNRS, a logística reversa, o inventário de geração de resíduos e a gestão integrada dos resíduos são pontos fundamentais da política e vão preencher grandes vazios legislativos no Brasil ${ }^{[8]}$.

Segundo a Associação Brasileira das Empresas de Limpeza Pública e Resíduos Especiais (ABRELPE), a lei sancionada traz avanços para o setor e dentre os pontos positivos são destacados, a logística reversa, a responsabilidade compartilhada e o princípio da hierarquia na gestão. Como ponto negativo, a lei não indica as fontes de recursos para custear as mudanças, nem aponta as linhas de financiamento, benefícios econômicos e fiscais para o setor. Deve ser feito um detalhamento para a implementação da logística reversa na prática, responsabilidade compartilhada e os acordos setoriais ${ }^{[9]}$. 
Segundo Eduardo de Souza Martins, a PNRS é um marco regulatório para o lixo, seja ele reaproveitável ou não. No caso dos pneus inservíveis já existe uma legislação para a coleta e descarte ${ }^{[10]}$.

\section{Logística Reversa}

O conceito de logística reversa surgiu há muito tempo atrás. Em 1970, surgiram definições como canais reversos ou fluxo reverso que apareceram na literatura cientifica, mas eram relativos à reciclagem.

No Brasil, a logística reversa é um novo conceito da logística empresarial, que surgiu na década de 90, quando foi reconhecido pelos profissionais de logística que matérias-primas, componentes e suprimentos representavam custos significativos que devem ser administrados de forma adequada, quando do seu retorno de pósvenda ou pós-consumo.

Em 1993, Ballou ${ }^{[11]}$ já demonstrava a preocupação com a geração de resíduos sólidos em função do aumento da população, industrialização, crescimento do uso de embalagens e produtos descartáveis, que indicavam uma despreocupação com a reciclagem no final da vida útil. Os canais de retorno para estes produtos eram pouco desenvolvidos e eficientes e as empresas não utilizavam os materiais reciclados devido ao custo de aquisição ser maior quando comparado a matérias-primas virgens, isso demonstrava o descaso com a utilização dos resíduos sólidos como fontes de matéria-prima.

A logística reversa está associada ao retorno de produtos pós-venda para a reforma, reparos, remanufaturas, substituição de materiais; e pós-consumo para a reutilização, reciclagem, valorização energética; e a disposição final dos produtos no final da vida útil.

Segundo Dekker ${ }^{[12]}$, existem 5 tipos de retorno de produtos e serviços:

- Retrabalho durante a fabricação de um produto ou serviço;

- Retornos comerciais para novas vendas ou remanufatura, devido ao excesso de estoque, produto vencido ou retorno dos clientes;

- Retorno em garantia, para reparo, remanufatura, avaliação técnica com a posterior troca do produto;

- Retorno final de uso nos contratos de leasing, máquinas e equipamentos alugados; e

- Retorno no final da vida útil para a remanufatura, reutilização, reciclagem ou valorização energética.

O pós-venda e o pós-consumo ganham importância nas estratégias de sustentabilidade e no crescimento dos negócios das empresas. A partir da aprovação de legislações restritivas com relação à disposição final dos produtos no final da vida útil nos países do primeiro mundo e emergentes, algumas empresas aceitam previamente o retorno dos seus produtos dos consumidores finais, para uma possível reutilização, reciclagem no seu ciclo produtivo ou em outros ciclos, ou mesmo para a disposição final.

O Council of Logistics Management (1993) publicou a primeira definição conhecida para a logística reversa no início dos anos 90, definindo-a como um termo utilizado com regra para a logística da reciclagem, disposição de resíduos, gerenciamento de resíduos perigosos. Uma ampla perspectiva incluindo tudo relacionado às atividades logísticas e recursos para a redução, reciclagem, substituição, reuso dos materiais e disposição ${ }^{[13]}$.

Em 1993, o CLM definiu a logística reversa como um amplo termo relacionado às habilidades e atividades envolvidas no gerenciamento de redução, movimentação e disposição de resíduos de produtos e embalagens.

O Council of Supplier Chain Management Professionals (2010) define a logística reversa como o segmento especializado da logística focado na movimentação e gerenciamento do produto e recursos pós-venda ao cliente, incluindo o retorno de produtos para reparos ou créditos ${ }^{[14]}$.
O grupo de trabalho europeu sobre a logística reversa (Revlog), definiu-a como o processo de planejamento, implementação e controle dos fluxos de materiais no processo de estoque e produto acabado, desde a fabricação e distribuição ou do ponto de utilização ao ponto de recuperação ou ponto para a disposição final[15].

Roggers e Tibben-Lembke (1998) definiram a logística reversa como o processo de planejamento, implementação e controle da eficiência, custo efetivo do fluxo de matérias-primas, estoques, produtos acabados e informações relativas do ponto de consumo até a origem, com o propósito de recuperar o valor ou adequar o seu $\operatorname{destino~}^{[16]}$.

Pochampally, Nukala e Gupta (2009) definiu a cadeia reversa como uma série de atividades necessárias à coleta de produtos usados dos consumidores, reprocesso e recuperação de seu valor residual no mercado ou para a disposição ${ }^{[17]}$.

Segundo Paulo Roberto Leite (2009), a logística reversa é definida como o fluxo de materiais de pós-consumo até a sua reintegração ao ciclo produtivo, na forma de um produto equivalente ou diverso do produto original, ou retorno do bem usado ao mercado ${ }^{[18]}$.

A logística reversa é um dos principais processos dentro da cadeia de reciclagem, que viabiliza economicamente e mantém a constância em toda a cadeia, seja ela para o processo de reutilização, reciclagem ou valorização energética. No caso dos pneus, a maior dificuldade é a realização da coleta e do transporte, pois em muitos casos, esses pneus estão localizados em regiões de difícil acesso, o que torna o processo inviável do ponto de vista econômico pelo custo logístico.

\section{Reciclagem de Pneus}

Os pneus são descartados quando trocados por novos ou quando os carros, caminhões e ônibus chegam ao final da sua vida útil. Em muitos países os pneus usados são deixados em centros de coleta e os consumidores pagam uma taxa que financia a logística reversa. A partir deste momento é feita uma triagem, analisando se as carcaças dos pneus têm condição ou não de serem utilizadas no processo de reforma. As que têm condições são encaminhadas às empresas que fazem a recauchutagem, as que não apresentam condições de serem reformadas são encaminhadas para as empresas de reciclagem e valorização energética.

\section{Reciclagem de pneus no Brasil}

O sistema implementado no Brasil é o sistema de retorno com responsabilidade dos fabricantes e dos importadores. O sistema é semelhante ao utilizado pelos países membros da Comunidade Européia, com exceção do pagamento da taxa paga pelos consumidores, no momento da troca dos pneus usados por novos.

O grande desafio para a cadeia da reciclagem de pneus inservíveis é a realização de uma coleta mais eficiente. O custo da coleta e do transporte dos pneus usados, mesmo na Europa e nos Estados Unidos, independente das alternativas que venham a ser encontradas, apresenta-se como a primeira grande dificuldade para a solução definitiva do descarte de pneus usados ${ }^{[19]}$. Está claro que o problema causado pelos pneus está relacionado à dificuldade de identificar quem é o responsável por sua disposição. As fontes geradoras são os consumidores que descartam os seus pneus usados após a troca nas revendas e distribuidores, ou levam os pneus usados para casa após a troca, muitas das vezes são descartados de forma incorreta.

Segundo estudo realizado pelo Instituto de Pesquisas Tecnológicas (IPT), em 2006 dos 100\% vendidos no mercado de reposição, 54,1\% foram considerados servíveis e $44,7 \%$ inservíveis. Do total de pneus servíveis $13,2 \%$ ficaram retidos com os consumidores, deste total, 
7,5\% são doados ou vendidos e 5,8\% para uso próprio, o restante é considerado inservível ${ }^{[20]}$.

\section{Reciclagem de pneus pelos fabricantes}

Desde 1999 até $1^{\circ}$ semestre de 2011 foram reciclados 1,71 milhão de toneladas, o equivalente a 342 milhões de pneus de automóvel. O investimento realizado pela indústria de pneumáticos até o $1^{\circ}$ semestre de 2011 foi de US\$ 143,6 milhões, com custo para coleta, pré-tratamento e destinação de US\$ 0,42 por pneu ${ }^{[21]}$.

O Estado de São Paulo, coleta mensalmente 7.500 t de pneus inservíveis $^{[22]}$, o equivalente a 1,5 milhões de pneus inservíveis de automóveis, que são destinados para empresas de reciclagem ou valorização energética. $\mathrm{O}$ volume coletado é maior que a capacidade instalada, ou seja, o excedente é enviado para destinação final nos Estados de Minas Gerais e Paraná

A quantidade reciclada de pneus no período de 2002 até 2010 e a previsão para a reciclagem dos pneus inservíveis é apresentada na Figura 2.

Com a aprovação da PNRS, as tendências para a reciclagem de pneus no Brasil são:

- O envolvimento das revendas, distribuidores, borracheiros, associações dos fabricantes, importadores, recicladores, consumidores, órgãos ambientais e poder público, no processo de coleta e destinação dos pneus inservíveis;

- Controle sobre o fluxo de pneus usados, por parte dos estados;

- Redução do custo da coleta e destinação;

- Incentivo a novas pesquisas e a criação de novos mercados para a utilização de produtos ou matéria-prima de pneus inservíveis reciclados;

- Aumento da conscientização da população com relação à necessidade da destinação dos pneus no final da vida útil;

- Desenvolvimento de novas matérias-primas para a utilização na construção de pneus, que facilitem a reciclagem; e

- Mudança do conceito de resíduo para matéria-prima, ou combustível alternativo, para a utilização no coprocessamento, queima em caldeiras na indústria de papel e celulose, entre outras, tornando a cadeia da reciclagem de pneus um negócio auto-sustentável.
Em 2010, os fabricantes destinaram: 64\%, para o coprocessamento; $32 \%$ granulado, pó de borracha, artefatos e aço; $4 \%$, para o processo de laminação, conforme a Figura 3.

No diagrama de blocos do processo de logística, será detalhado o fluxo da logística reversa dos pneus usados, conforme a Figura 4.

Controle federal (IBAMA)

O IBAMA faz a fiscalização, controle e reportagem das metas de reciclagem $\times$ pneus destinados, recebendo informações dos fabricantes, importadores, exportadores, empresas de reciclagem e valorização energética, que são cadastradas no Cadastro Técnico Federal (CTF). Além disso, recebem informações da Secretaria de Comércio Exterior (SECEX), com relação à importação de pneus novos, exportação e pneus equipados em veículos.

Os pneus de veículos no final da vida útil não entram no cálculo da reciclagem de pneus devido à falta de legislação especifica.

\section{Criação de um controle nos estados}

Deve ser criado um controle estadual para a reciclagem de pneus, com o objetivo de controlar o fluxo dos pneus que entram no mercado de reposição até a sua destinação. Além disso, deve ser quantificado os pneus servíveis e inservíveis que vem de outros estados para o processo de reforma e reciclagem respectivamente.

\section{Consumidor}

O consumidor ao trocar o pneu usado por um pneu novo pode deixar o mesmo na loja para a reciclagem ou levá-lo para casa. Caso escolha deixar o pneu na loja, deve constar na nota fiscal, que o pneu usado foi deixado na loja para fim de destinação final.

Caso a opção for levá-lo para casa, deve constar na nota fiscal o ponto de coleta mais próximo para a destinação final.

Pontos de coleta

Além destes pontos, existe um programa de coleta dos pneus inservíveis que é desenvolvido por meio de parcerias com as prefeituras, que cedem os terrenos dentro de normas específicas de segurança e higiene para receber os pneus inservíveis.

O critério para a implantação dos pontos de coleta é a localização próximo dos centros geradores, de empresas de pré-tratamento, cimenteiras, laminadores e empresas que utilizam borracha dos

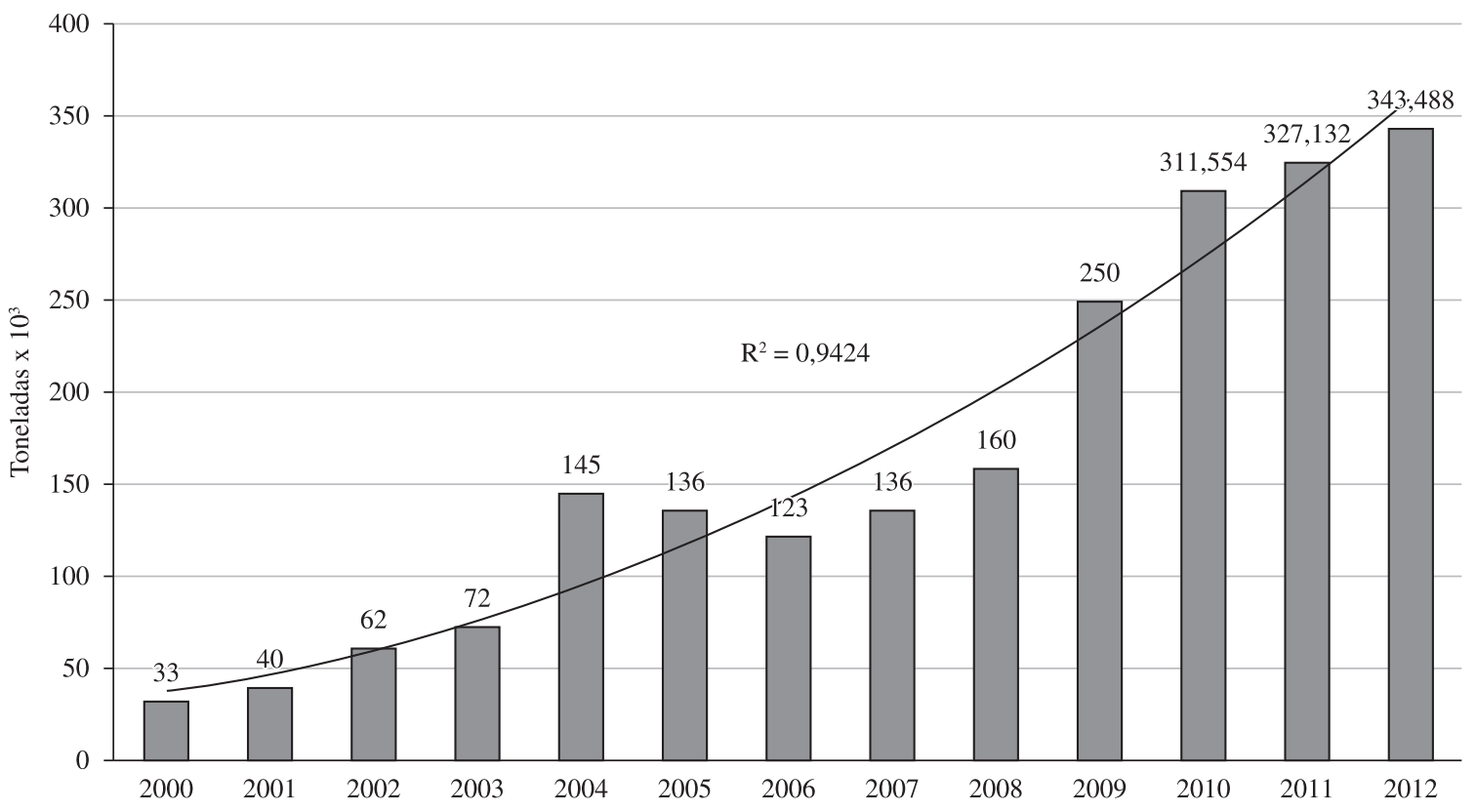

Figura 2. Quantidade destinada pelos fabricantes de pneus no período de 2000 a 2010 e a previsão para a destinação em 2011 e $2012^{[22-23]}$. 


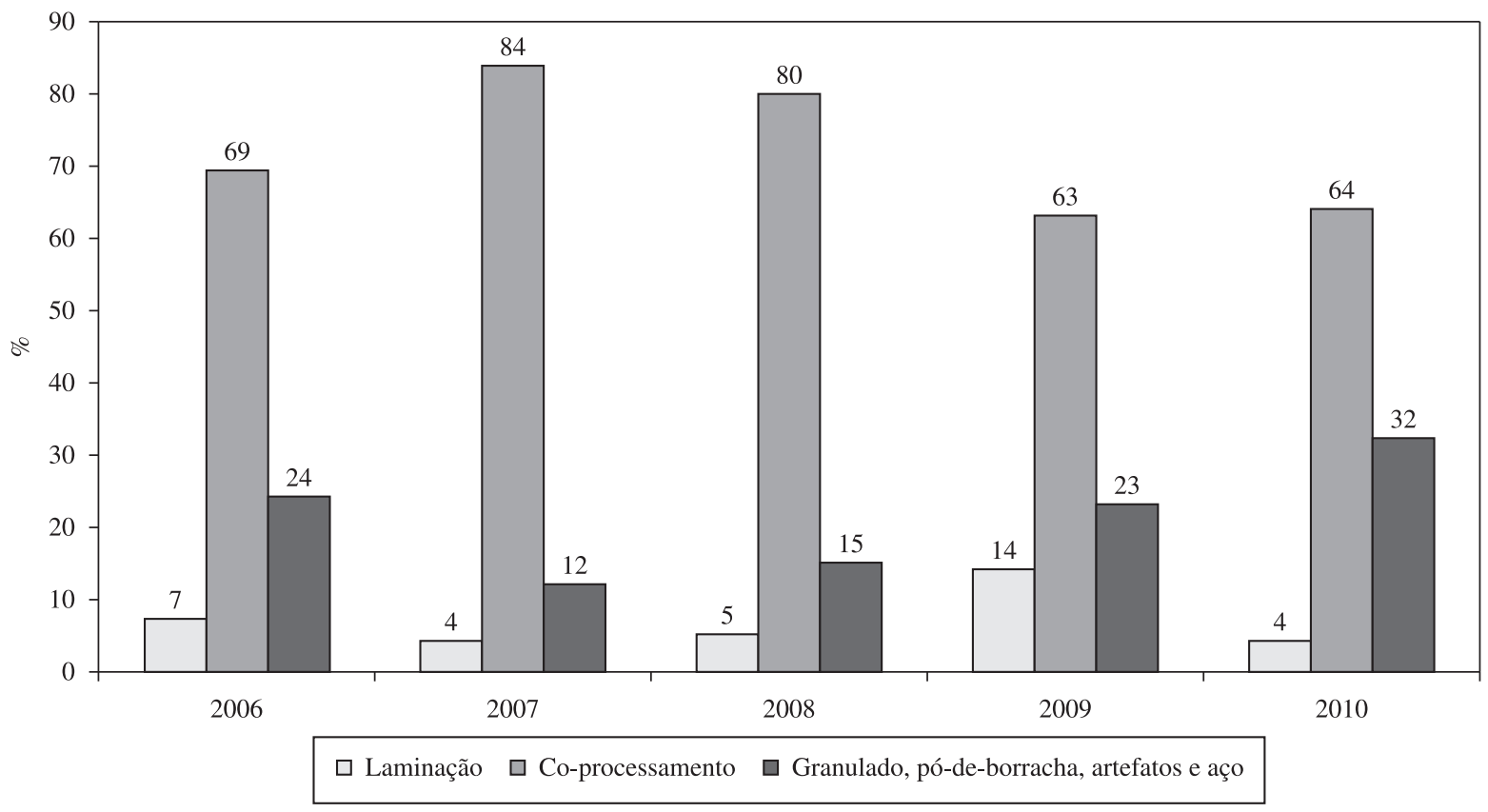

Figura 3. Destinação dos pneus inservíveis pelos fabricantes.

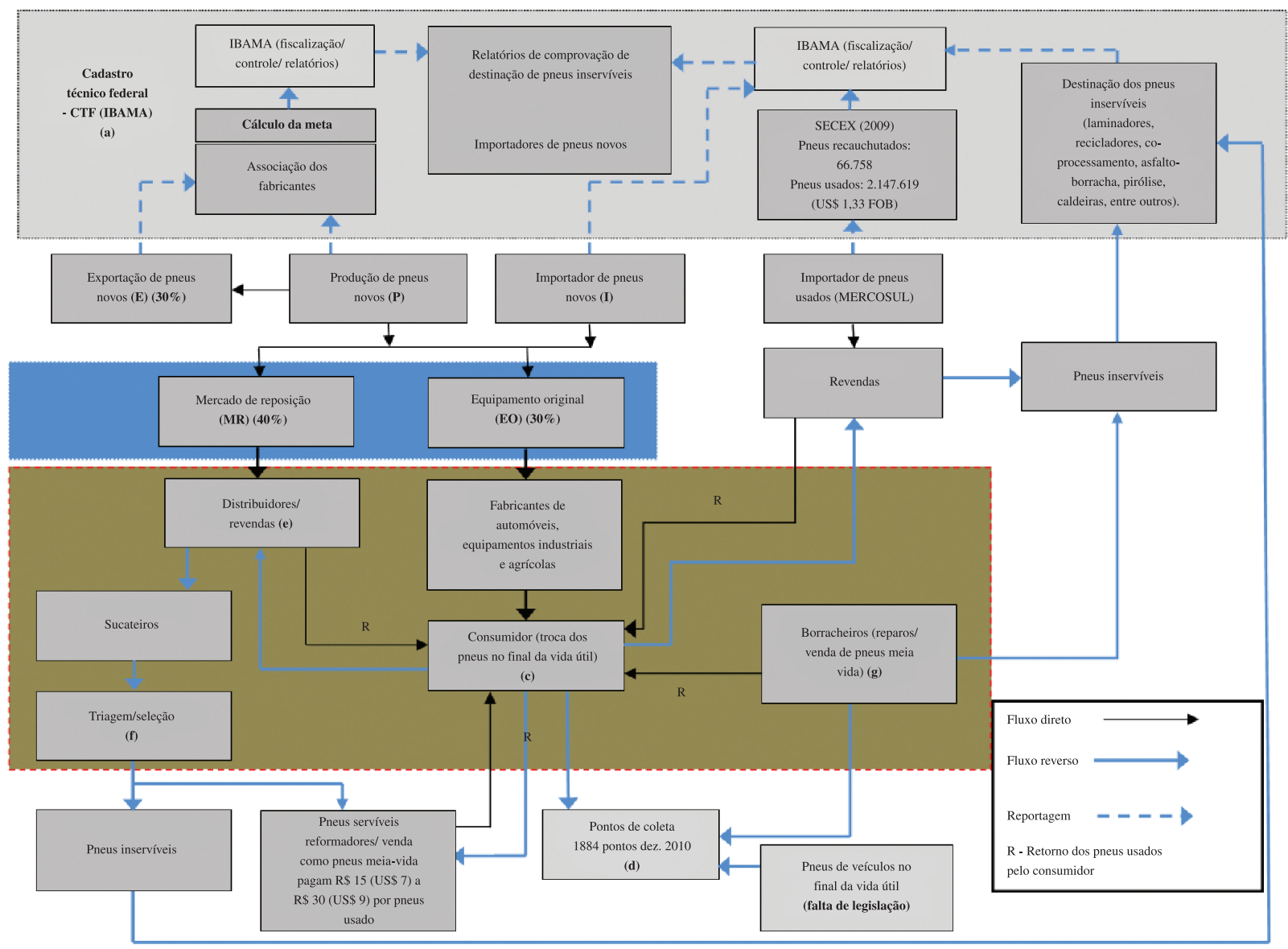

Figura 4. Diagrama de blocos da logística reversa dos pneus usados no Brasil. 
pneus inservíveis como matéria-prima para a fabricação de tapetes automotivos.

Os pontos de coleta de pneus são gerenciados pelas prefeituras que firmam convênio com a associação que representa os fabricantes. São responsáveis pelo armazenamento temporário, solicitação a associação que representa os fabricantes, com 72 horas de antecedência, para o carregamento das carretas e o transporte. $\mathrm{O}$ carregamento mínimo é de 2000 pneus de automóvel ou 300 pneus de carga, a frequência é estabelecida entre as partes após o início da operação. No Brasil, $98 \%$ do transporte de pneus são realizados por caminhões e $2 \%$ por barcos, principalmente na região norte. O caminhão deve ter a sua capacidade máxima preenchida, o que determina o fluxo de retirada dos pneus.

\section{Distribuidores e revendas}

Os distribuidores e revendedores participam do processo de reciclagem de pneus. A estratégia adotada pelos fabricantes foi utilizar as revendas e distribuidores, para fazer a coleta dos pneus usados, quando deixados pelos clientes de forma voluntária no momento da troca por pneus novos.

Os distribuidores e revendas têm duas opções para o encaminhamento dos pneus: empresas de triagem e seleção ou destinação final.

Em 2010, são 4.000 revendas de pneus no país que participam do processo de coleta e destinação dos pneus.

\section{Empresas de triagem e seleção}

Os pneus usados são coletados nas revendas e distribuidores, em seguida são encaminhados para empresas que fazem a seleção e triagem.

No processo de triagem os pneus são classificados em servíveis ou inservíveis, os pneus servíveis são vendidos como pneus meia-vida ou encaminhados para empresas de recauchutagem; os pneus inservíveis são destinados a empresas que fazem o pré-tratamento.

As empresas de triagem e seleção devem classificar os pneus como servíveis ou inservíveis, emitir uma nota fiscal para o envio dos pneus inservíveis para os pontos de coleta ou para a destinação final, e uma nota fiscal para a venda como pneus meia- vida ou para a indústria de reforma.

Em 1999, 65\% de todos os pneus coletados eram considerados inservíveis. Em 2004, 68\% eram considerados inservíveis, $16 \%$ vendidos como pneus meia-vida e $16 \%$ eram destinados para a reforma ${ }^{[24]}$. Em 2007, 30\% dos pneus usados podiam ser reformadas $^{[25]}$.

\section{Borracharias}

Os borracheiros que vendem os pneus meia-vida, ou trocam pneus novos que geralmente são levados pelos proprietários dos veículos para a troca, devem levar os pneus inservíveis até um ponto de coleta. Deve ser feito um controle do fluxo de pneus que são encaminhados para a reciclagem, coletados nas borracharias.

\section{Comparativo entre os sistemas para a reciclagem de pneus no Japão, Estados Unidos, Comunidade Européia e Brasil}

Um comparativo dos sistemas implementados, tecnologias utilizadas para a reutilização, reciclagem e valorização energética, taxas para a coleta e custo para a reciclagem de pneus é apresentado na Tabela 1. Na Comunidade Européia, 48,3 \% dos países utilizam o sistema de responsabilidade do fabricante e importador.

Com relação à disposição de pneus em aterros na Comunidade Européia, todos os países membros são proibidos de enviar para aterros pneus inservíveis inteiros ou triturados. Pode-se observar que apesar da proibição, a prática ainda é comum em alguns países.
No Brasil, não existe nenhum inventário sobre a disposição dos pneus inservíveis em aterros e lixões.

\section{Cumprimento da Resolução CONAMA n ${ }^{0}$ 258/99 e n 416/09}

Em julho de 2011, foi publicado pelo IBAMA o Relatório de Pneumáticos ${ }^{[26]}$, referente a reciclagem de pneus inservíveis no período de outubro de 2009 a dezembro de 2010. Os dados foram obtidos no CTF do IBAMA. O relatório apresenta informações consolidadas de 15 fabricantes de pneus e 466 importadoras de pneus novos. A meta para a destinação no período foi de 560.337,63 t, com destinação de 555.107,62 t, o que representa 99,07\% da reciclagem, sendo $105,88 \%$ reciclados pelos fabricantes e $87,04 \%$, pelos importadores.

No período de outubro a dezembro de 2010, 466 empresas importadoras estavam cadastradas no CTF, reciclando no período apenas $87,04 \%$ da meta, que era de 202.594,52 t. Segundo o relatório de pneumáticos ${ }^{[26]}$, houve um retrocesso no cumprimento da meta pelas empresas importadoras de pneus novos, quando comparado com as metas estabelecidas pela Resolução CONAMA n 258/99, revogada pela $n^{\circ} 416 / 09$.

No período de 2002 a outubro de 2009, os importadores de pneus novos tinham que comprovar a destinação dos pneus para obter a aprovação da Licença de Importação (LI).

Quando vigorava a Resolução CONAMA no 258/99, os importadores de pneus novos tinham de comprovar a destinação antes do embarque da mercadoria porque o IBAMA, órgão anuente da atividade, só liberava a importação mediante a comprovação da destinação de pneus inservíveis. Assim, os importadores sempre cumpriram as metas de destinação.

Com a aprovação da Resolução n ${ }^{\circ}$ 416/09, o IBAMA deixou de ser anuente, pois a comprovação de destinação é feita posteriormente ao recebimento dos pneus novos. As empresas importadoras passaram a ter até um ano para comprovar a destinação ${ }^{[26]}$.

Segundo o IBAMA ${ }^{[26]}$, algumas empresas importadoras de pneus mesmo notificadas não cumpriram as metas de reciclagem, cabendo ao instituto a aplicação de medidas administrativas cabíveis, objetivando o cumprimento da meta estabelecida.

No período de outubro de 2009 a dezembro de 2010, foram vendidos no mercado de reposição 52.769 .776 pneus, o que corresponde a $800.482,34 \mathrm{t}$, sendo que $79,04 \%$ dos pneus foram produzidos no Brasil e 20,96\% importados ${ }^{[26]}$. A meta para a reciclagem de pneus inservíveis era de 560.337,63 t.

No mesmo período, foram destinados pelos fabricantes $378.774,09$ t de pneus inservíveis, o que corresponde a 105,88\% da meta de reciclagem. As 15 empresas fabricantes de pneus cumpriram, no período de outubro de 2009 a dezembro de 2010, a meta de destinação conjuntamente e individualmente pelo Cadastro Nacional de Pessoa Jurídica (CNPJ) de cada empresa ${ }^{[26]}$.

A Figura 5 apresenta a evolução da reciclagem de pneus no Brasil, após a aprovação da Resolução no 258/99, no período de 2002 à setembro de 2009.

Em 2010, os tipos de destinação constantes no formulário do $\mathrm{CTF}$, preenchido pelas empresas destinadoras, foram ${ }^{[26]}$ :

- Coprocessamento em cimenteiras: empresas que se dedicam à fabricação de cimentos e que coprocessam os pneus inservíveis inteiros ou triturados nos fornos de clínquer em substituição parcial de matéria-prima e combustível alternativo;

- Trituradora: empresa que tritura os pneus inservíveis em chips para o envio às empresas cimenteiras;

- Laminadora: empresa que faz a laminação de pneus diagonais/ convencionais e fabrica os artefatos de borracha; 


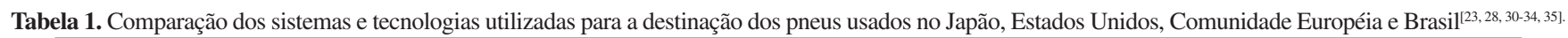

\begin{tabular}{|c|c|c|c|c|}
\hline & Japão & Estados Unidos & $\begin{array}{l}\text { Comunidade Européia } \\
(\text { CE 27+2) }\end{array}$ & Brasil \\
\hline & 2009 & 2007 & 2008 & 2009 \\
\hline Sistema Implementado (1) & ML & ML & $\mathrm{RF} / \mathrm{ML} / \mathrm{ST}$ & RF \\
\hline Meta para a Reciclagem de Pneus & $\begin{array}{c}\text { Mercado de Reposição + } \\
\text { Pneus retirados dos veículos } \\
\text { no final da vida útil }\end{array}$ & $\begin{array}{c}\text { Mercado de Reposição + } \\
\text { Pneus retirados dos veículos } \\
\text { no final da vida útil }\end{array}$ & $\begin{array}{c}\text { Mercado de Reposição + } \\
\text { Pneus retirados dos veículos } \\
\text { no final da vida útil }\end{array}$ & $\begin{array}{l}\text { Mercado de } \\
\text { Reposição }\end{array}$ \\
\hline Taxa (Financia todo o processo de logística reversa) & $\mathrm{Nd}$ & US\$ 0,25 a 5 & $\begin{array}{l}\text { Portugal } € 1 ; \text { França } € 1,5 \\
\text { Alemanha } € 2 \text { a } 3\end{array}$ & $\begin{array}{c}\text { Sistema financiado } \\
\text { pelos fabricantes e } \\
\text { importadores }\end{array}$ \\
\hline Total Reciclado (ton. $\times 10^{3}$ ) & 1.187 & $4.595,70$ & 3.281 & 250 \\
\hline Taxa de Reciclagem (\%") & 89 & 89,3 & 95 & (2) \\
\hline $\begin{array}{l}\text { Custo para a reciclagem de pneus (coleta, } \\
\text { pré-tratamento e destinação final) }\end{array}$ & $\mathrm{Nd}$ & $\mathrm{Nd}$ & França $€ 1,78 /$ pneu & US\$ 0,48 / pneu \\
\hline Recauchutagem / Recapagem ton. $\times 10^{3}$ & 46 & $\begin{array}{l}\text { Não é considerada uma } \\
\text { atividade de reciclagem }\end{array}$ & 358 & $\begin{array}{l}\text { Não é considerada } \\
\text { uma atividade de } \\
\text { reciclagem }\end{array}$ \\
\hline Recuperação / pó de borracha / piso ton. $\times 10^{3}$ & 83 & 791 & 1273 & 45 \\
\hline Outros usos ton. $\times 10^{3}$ & 7 & & & 35 \\
\hline Obras de Engenharia ton $\times 10^{3}$ & & 561,6 & & 2,5 \\
\hline Coprocessamento na indústria de cimento ton. $\times 10^{3}$ & 349 & 669,1 & \multirow{8}{*}{1199} & \\
\hline Caldeiras Industriais ton. $\times 10^{3}$ & 9 & 200,6 & & \\
\hline Indústria Siderúrgica ton. $\times 10^{3}$ & 28 & 27,1 & & 10 \\
\hline Indústria Metalúrgica ton. $\times 10^{3}$ & 1 & & & \\
\hline Forno de Gaseificação ton. $\times 10^{3}$ & 48 & & & \\
\hline Indústria de Pneumáticos ton. $\times 10^{3}$ & 18 & & & \\
\hline Indústria de Papel ton. $\times 10^{3}$ & 349 & 1066,9 & & \\
\hline Geração de Eletricidade ton. $\times 10^{3}$ & 11 & 547,3 & & \\
\hline Exportação para reutilização e reforma ton. $\times 10^{3}$ & 148 & 102,1 & 273 & \\
\hline Projetos de recuperação ton. $\times 10^{3}$ & 3 & 132,6 & $\mathrm{Nd}$ & \\
\hline Estoque nos distribuidores ton. $\times 10^{3}$ & 87 & & & \\
\hline Disposição em Aterros ton. $\times 10^{3}$ & 42 & 594 & $195(3)$ & $\begin{array}{c}\text { Não existe um } \\
\text { inventário da } \\
\text { disposição de } \\
\text { pneus inservíveis } \\
\text { no Brasil }\end{array}$ \\
\hline
\end{tabular}

(1) ML - Mercado Livre; RF - Responsabilidade do Fabricante; ST - Sistema de Taxas. (2) Não foi divulgada a destinação dos pneus inservíveis pelos importadores de pneus novos. No período de janeiro a setembro de 2009, foram recicladas 123.000 t de pneus inservíveis. O IBAMA divulgou o relatório de pneumáticos em julho de 2011, mas não consta a informação sobre o período 2009. (3) Proibida a disposição de pneus inservíveis em aterros desde julho de 2006, em todos os países membros da Comunidade Européia. Nd - Não disponível.

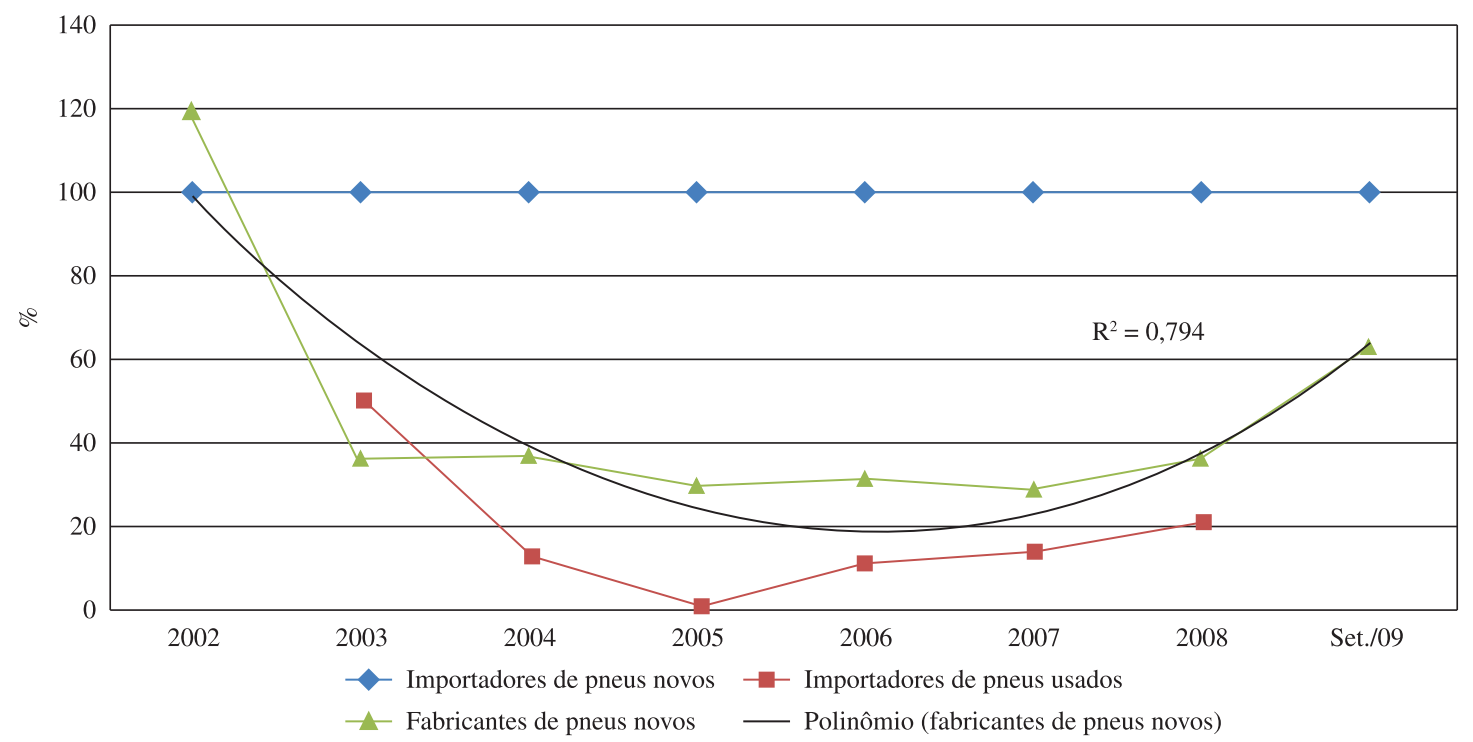

Figura 5. Cumprimento da Resolução no 258/99, no período de 2002 a setembro de 2009 ${ }^{[27]}$. 
- Recicladora: empresa que tritura e granula os pneus inservíveis, separando o aço e as fibras têxteis utilizadas na construção dos pneus, com produto final pó de borracha e aço; e

- Coprocessamento no processo Petrosix: empresa que faz o coprocessamento da rocha de xisto pirobetuminoso com os pneus inservíveis.

O coprocessamento em cimenteiras é responsável por 49,87\% das destinações realizadas. Os pneus triturados em chips são enviados posteriormente às empresas cimenteiras e representam $4,01 \%$ do total, conforme a Tabela 2.

Como a Resolução n ${ }^{\circ} 416 / 09$ passou a vigorar a partir de outubro de 2009, os dados apresentados no relatório de pneumáticos, referem-se ao último trimestre de 2009 até dezembro de 2010. Segundo o IBAMA (2011), devido a forma de funcionamento do sistema de inserção das informações, não foi possível, para o primeiro relatório da Resolução ${ }^{\circ}$ 416/09, separar os dois períodos.

O relatório de pneumáticos do IBAMA, conforme a Resolução n * 416/09 e Instrução Normativa n ${ }^{\circ}$ 001/10, não divulgou a destinação dos pneus inservíveis para a utilização no asfalto-borracha, pirólise, ou em caldeiras. Como as empresas de destinação cadastradas no CTF têm mais de uma destinação, não é divulgada a quantidade para a reciclagem e a valorização energética.
Com relação à capacidade ociosa das empresas de trituração/ granulação, laminação e operadores logísticos associados, o índice foi de $15 \%$ em 2010.

\section{Evolução dos Pontos de Coleta no Brasil após a aprovação da Resolução n 416/09}

A partir da aprovação da Resolução n ${ }^{\circ} 416 / 09$, obrigando os fabricantes e importadores de pneus a implementarem pontos de coleta em cidades com mais de 100.000 habitantes, foram montadas unidades de forma individual ou compartilhada, podendo envolver as revendas e distribuidores; os municípios, os borracheiros, entre outros.

Foram cadastrados, entre outubro de 2009 e dezembro de 2010 , 1.884 pontos de coleta $^{[26]}$, sendo que $73,04 \%$ estão instalados em municípios com população acima de 100.000 habitantes. Do total de pontos de coleta implementados no Brasil, $75,75 \%$ estão localizados nas Regiões Sul e Sudeste, conforme a Figura 6.

Os responsáveis pelo cadastro dos pontos de coleta no CTF são os fabricantes e importadores de pneus. Não existe no CTF a quantificação dos pontos de coleta em revendas e distribuidores, borracheiros e municípios.

Tabela 2. Destinação dos pneus inservíveis no período de outubro de 2009 a dezembro de 2010 , conforme o CTF ${ }^{[26]}$.

\begin{tabular}{lcc}
\hline \multicolumn{1}{c}{ Tipo de Destinação } & Quantidade Destinada (t) & $(\%)$ \\
\hline 1 - Coprocessamento nas cimenteiras & $281.357,83$ & 49,87 \\
2 - Recicladora & $97.194,16$ & 17,23 \\
3 - Laminadora & $66.239,08$ & 11,74 \\
4 - Recicladora/Regeneradora & $38.413,34$ & 6,81 \\
5 - Recicladora/Trituradora & $25.151,11$ & 4,46 \\
6 - Trituradora & $22.637,59$ & 4,01 \\
7 - Recicladora/Laminadora & $22.434,68$ \\
8 - Coprocessamento processo Petrosix & $7.549,51$ \\
9 - Recicladora/Laminadora/Trituradora & $3.040,94$ \\
10 - Regeneradora & 118,28 \\
11 - Recicladora/Trituradora/Regeneradora & 9,58 \\
Total geral & $564.146,10$ & 0,54 \\
\hline
\end{tabular}

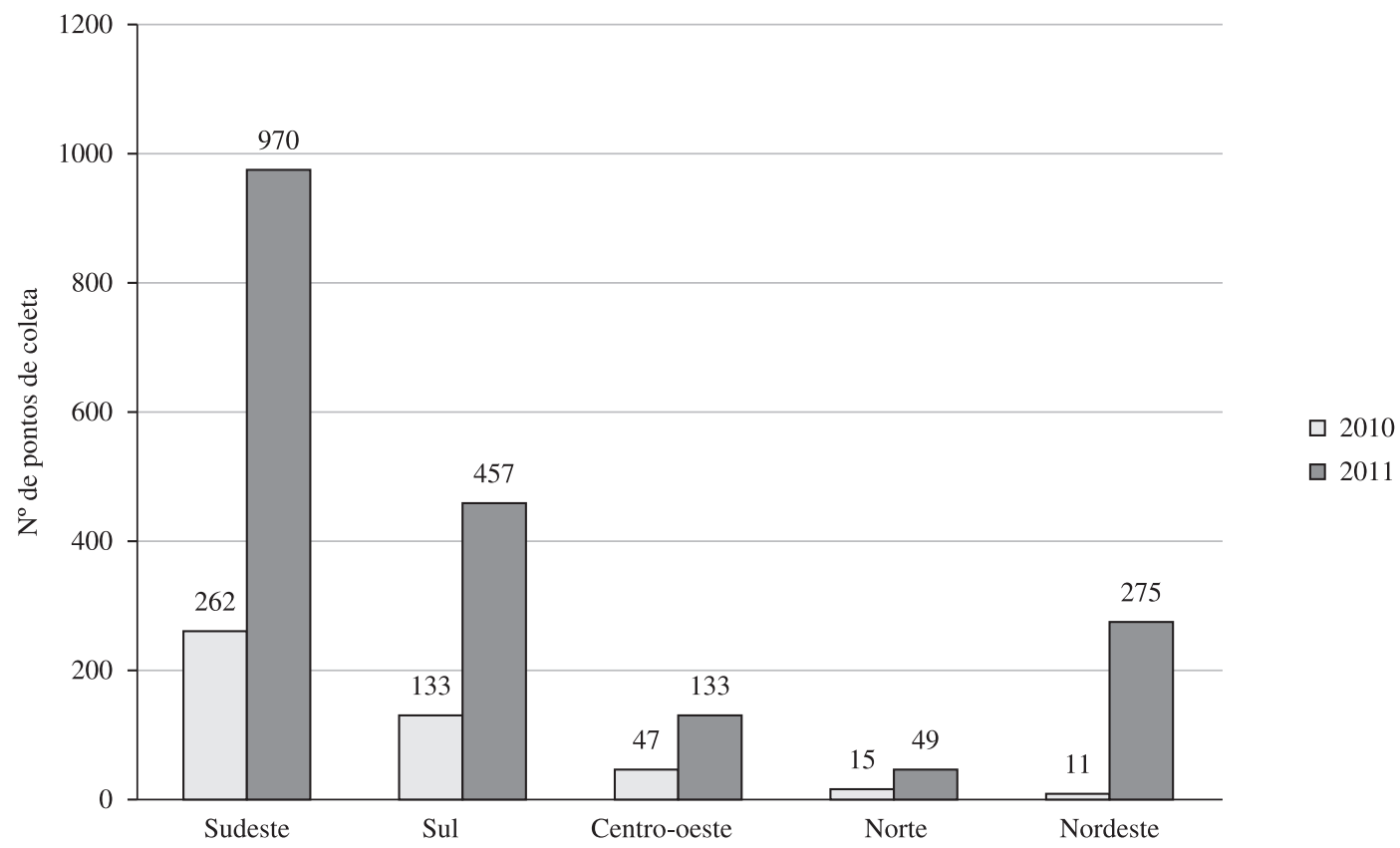

Figura 6. Localização dos pontos de coleta por região, 31 de março de 2011. 


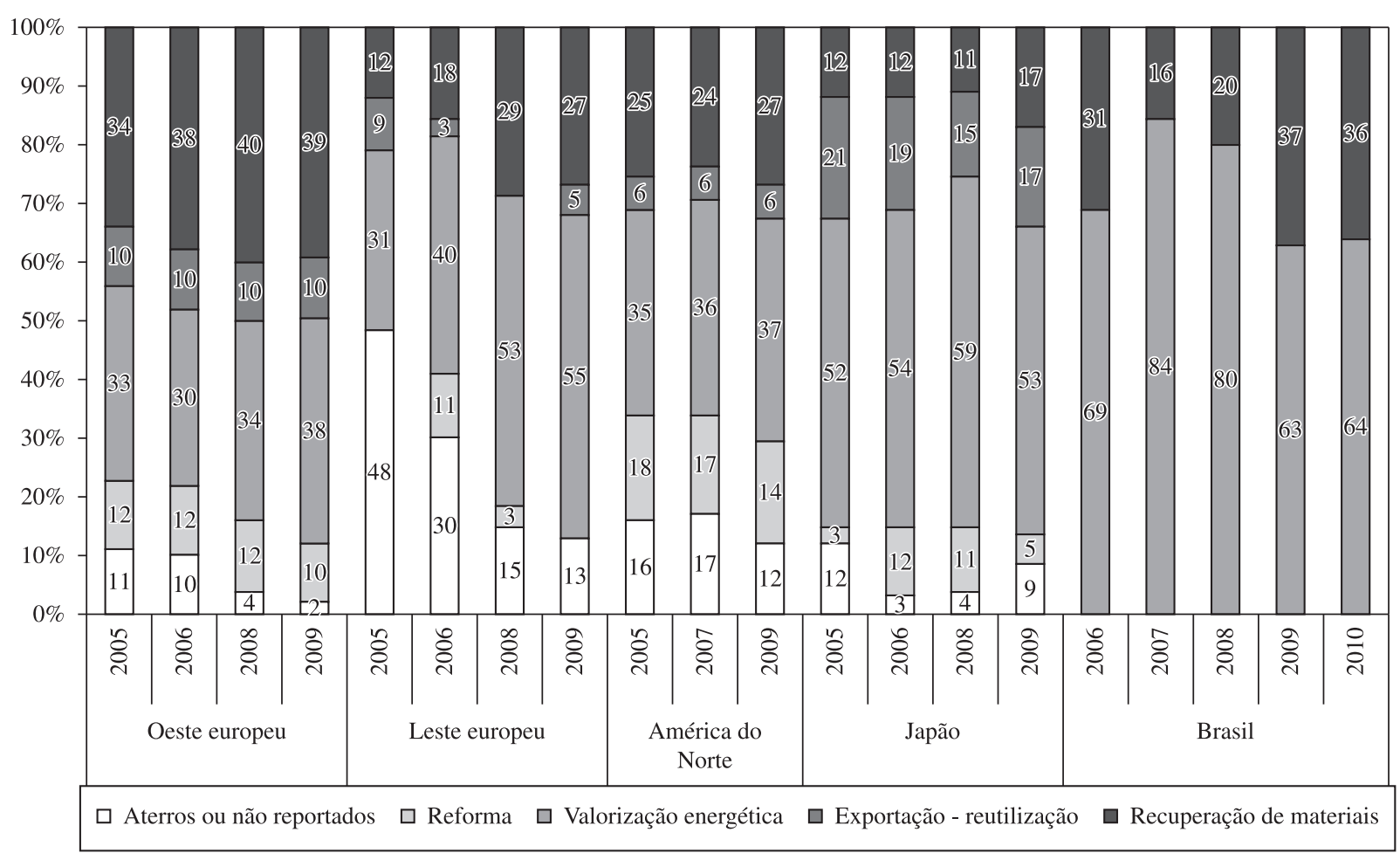

Figura 7. Reciclagem de pneus na Europa, América do Norte, Japão e Brasil ${ }^{[23,28-35]}$.

Com relação às especificações para a montagem de um ponto de coleta, não existe uma legislação, o que há é a proibição para a armazenagem dos pneus a céu aberto.

\section{Comparativo da reciclagem de pneus no Brasil, Europa e América do Norte}

Comparando os resultados obtidos no Brasil, Europa e América do Norte, pode-se observar a tendência no Brasil do aumento da quantidade de pneus inservíveis enviados para valorização energética. Na Europa, uma das tendências verificadas foi a destinação dos pneus inservíveis para a reciclagem de materiais, conforme a Figura 7. No Brasil, os dados foram fornecidos pela associação que representa os fabricantes. A atividade de reforma e a reutilização de pneus não entram na estatística de reciclagem de pneus inservíveis ${ }^{[36]}$.

\section{Conclusão}

No Brasil, não existe nenhum incentivo por parte do governo para a reciclagem de pneus. Todo o processo de logística reversa é financiado pelos fabricantes e importadores de pneus novos.

Um grande desafio para a reciclagem de pneus é a mudança do conceito de resíduo para matéria-prima secundária, ou combustível alternativo para indústria de cimento, coprocessamento com a rocha de xisto pirobetuminoso e queima em caldeiras na indústria de papel, entre outras, tornando a cadeia da reciclagem de pneus um negócio auto-sustentável.

A responsabilidade compartilhada entre fabricantes, importadores, distribuidores, revendas, borracheiros e recicladores, deve facilitar a coleta, com redução de custos logísticos e destinação dos pneus usados no Brasil. Deve ser implementado um controle do fluxo de pneus usados dentro de cada estado.

\section{Referências Bibliográficas}

1. Brasil. Conselho Nacional do Meio Ambiente. - "Política Nacional de Resíduos Sólidos - PNRS, projeto de lei”, Congresso Nacional, Brasília
(2010). Disponível em: <www.camara.gov.br/sileg/integras/501911. pdf $>$. Acesso em: 10 ago. 2010.

2. Brasil. Conselho Nacional do Meio Ambiente. - "Decreto no 7.404, de 23 de dezembro de 2010. Regulamenta a Lei no 12.305, de 2 de agosto de 2010, que institui a Política Nacional de Resíduos Sólidos, cria o Comitê Interministerial da Política Nacional de Resíduos Sólidos e o Comitê Orientador para a Implantação dos Sistemas de Logística Reversa, e dá outras providências", Diário Oficial da República Federativa do Brasil, Brasília, 23 dez. (2010).

3. Associação Nacional das Indústrias de Pneumáticos - ANIP. - "Produção na Indústria Brasileira e Reciclagem de Pneus", ANIP, São Paulo (2010). Disponível em: <http://www.anip.com.br>. Acesso em: 19 ago. 2011.

4. Brasil. Conselho Nacional do Meio Ambiente. - "Resoluções do CONAMA, entre julho de 1984 a novembro de 2008", CONAMA, Brasília, (2008).

5. Instituto Brasileiro do Meio Ambiente e dos Recursos Naturais Renováveis - IBAMA. - "Instrução Normativa $\mathrm{n}^{\circ}$ 8, de 15 de maio de 2002", IBAMA, Brasília (2002). Disponível em: <http://www. ibama.gov.br>. Acesso em: 10 out. 2010.

6. Brasil. Conselho Nacional do Meio Ambiente. - "Resolução n ${ }^{\circ}$ 416, 20 de setembro de 2009", IBAMA, Brasília (2009). Disponível em: <http://www.mma.gov.br/port/CONAMA/>. Acesso em: 10 out. 2009.

7. Instituto Brasileiro do Meio Ambiente e dos Recursos Naturais Renováveis - IBAMA. - "Instrução Normativa no 01, de 18 de março de 2010", IBAMA, Brasília (2010). Disponível em: <www.ibama.gov. br>. Acesso em: 10 out. 2010.

8. Costa, F. D. - Rev. Sustentabilidade, p.1 (2010).

9. Silva Filho, C. R. V. - "Política Nacional de Resíduos Sólidos, visão da Associação Brasileira de Limpeza Pública e Resíduos Especiais", ABRELPE (2010). [mensagem pessoal] Mensagem recebida por: <carlos@abrelpe.org.br>em: 04 de agosto de 2010.

10. Martins, E. S. - "A construção de um programa que já reciclou mais de 240 milhões de pneus inservíveis", RECICLANIP, São Paulo 
(2010). Disponível em: <http://www.reciclanip.com.br>. Acesso em: 10 nov. 2010

11. Ballou, R. H. - "Logística empresarial: transporte, administração de materiais e distribuição física", Atlas, São Paulo, (1993).

12. Dekker, R. - "Reverse Logistics Impact, Trends and Issues. An European Network on Reverse Logistics - REVLOG", Erasmus University Rotterdam, The Netherlands (2001).

13. Council of Logistics Management. - "Reuse and recycling reverse logistics opportunities", Council of Logistics Management, Illinois (1993).

14. Council of Supplier CHAIN MANAGEMENT PROFESSIONAL. - "Reverse Logistics Definition", CSCMP, (2010). Disponível em: <http://www.cscmp.org/digital/glossary/glossary.asp>. Acesso em: 10 jun. 2010.

15. The European Working Group on Reverse Logistics. - "Reverse Logistics", REVLOG (2010). Disponível em: <http://www.fbk.eur.nl/ OZ/REVLOG/Publications.htm>. Acesso em: 10 jun. 2010.

16. Rogers, D. S. \& Tibben-Lemkle, R. S. - "Going Backwards: Reverse Logistics Trends and Practices", University Nevada, Reno (1998)

17. Pochampally, K. K.; Nukala, S. \& Gupta, S. M. - "Strategic Planning Models for Reverse and Closed-Loop Supply Chains", CRC Press, Boca Raton (2009).

18. Leite, P. R. - "Logística reversa meio ambiente e competitividade", Pearson Prentice Hall, São Paulo (2009).

19. Tegani, W. - "Reciclagem de pneus - situação atual e tendências", in: Anais do Workshop: Reciclagem de Veículos, Reciclagem de Pneus Situação Atual e Tendências, p.23, São Paulo - SP (1996).

20. Instituto de Pesquisas Tecnológicas do Estado de São Paulo - IPT. - "Relatório Técnico nº 91 136-205”, IPT, São Paulo (2006).

21. Reciclanip - "Consulta a Homepage", Reciclanip, São Paulo (2011). Disponível em: <http://www.reciclanip.com.br>. Acesso em: 12 ago. 2011.

22. Lagarinhos, C. A. F. - "Entrevista realizada com César Faccio - Gerente da Reciclanip, sobre o processo de coleta, tecnologias utilizadas para a reciclagem e destinação dos pneus inservíveis", RECICLANIP, São Paulo (2010)

23. Faccio, C. - "Para onde vai o pneu?", Reciclanip, São Paulo (2010)
24. Lagarinhos, C. A. F. - "Reciclagem de pneus: coleta e reciclagem de pneus. Co-processamento na indústria de cimento, Petrobras SIX e pavimentação asfáltica", IPT, São Paulo (2004).

25. Instituto Brasileiro de Meio Ambiente e dos Recursos Naturais Renováveis - IBAMA. - "Processo de Argüição de Descumprimento de Preceito Fundamental", n.101, Brasília (2007).

26. Instituto Brasileiro de Meio Ambiente e dos Recursos Naturais Renováveis - IBAMA. - "Relatório de Pneumáticos. Dados apresentados no Relatório de Pneumáticos - Resolução CONAMA n 4 416/09 do Cadastro Técnico Federal”, IBAMA, Brasília, 9p. (2011).

27. Aranha, R. - "Cumprimento da Resolução CONAMA no 258/99, no período de 2002 à setembro de 2009", IBAMA (2010). [mensagem pessoal] Mensagem recebida por: <pneus.sede@ibama.org.br> em: 08 de novembro de 2010 .

28. The Japan Automotive Tyre Manufactures Association. - "Tyre Industry of Japan 2010", Yokohama Rubber, Tokyo, (2010).

29. Lagarinhos, C. A. F. \& Tenório, J. A.S. - Engevista, 11, p.32 (2009).

30. European Tyre \& Rubber Manufacturers Association - "Annual Activity Report 2009-2010", ETRMA, Brussels, (2009).

31. Cinaralp, F. - "Experience of the Tyre Industry. Fiera di Ecomondo", Rimini (2009).

32. European Tyre \& Rubber Manufacturers Association. - "Annual Activity Report 2009 - 2010”, ET, RMA, Brussels (2010).

33. European Tyre \& Rubber Manufacturers Association. - "End of Life Tyres. a valuable resource with growing potential", ET, RMA, Brussels (2007).

34. European Tyre \& Rubber Manufacturers Association. - "EU National treatment data in 2008", ET, RMA, Brussels (2009).

35. Rubber Manufacturers Association RMA. - "Scrap Tire Market in The United States - Biennial Report", RMA, Washington (2009).

36. Lagarinhos, C. A. F. \& Tenório, J. A. S. Polímeros, 18, p.106-118 (2008). http://dx.doi.org/10.1590/S0104-14282008000200007

Enviado: 05/01/11

Reenviado: $30 / 08 / 11$

Aceito: 09/02/12 